ing records, and the application of these to the recording of the potentials in the human cerebral cortex. The magnitude of the potentials produced by the brain varies from 5 to 1,000 micro-volts; it is of alternating wave form, of frequencies ranging from 1 to 20 cycles per second, and very irregular. The frequency of the output from an abnormal brain (for example, epileptics and cases of cerebral tumours) differs appreciably from that of the normal, and from this and other indications it is claimed to be possible to diagnose mental diseases and locate with considerable accuracy the sites of tumours.

Although the records in most cases show a wave form of a main predominant frequency, this is frequently interrupted by irregular groups or bursts of waves of other frequencies. These irregularities have a definite clinical significance, and it is therefore of importance to analyse the record accurately to determine the frequencies present. The authors described a tuned reed autographic analyser which has been developed for this purpose, and showed an example of its application. The reading of the paper was accompanied by a demonstration on a human subject, in which the varying effects of permitting the brain to rest and of stimulating it into activity were shown by records on a cathode ray oscillograph.

\section{Golden Gate Bridge}

INSTRUMENTS have recently been installed on the Golden Gate Bridge at San Francisco for accurate recording of movements that occur under wind loads (Earthquake Notes, 14, Nos. 1 and 2; 1942). These include a wind velocity recorder, a wind directional recorder and a non-sensitive recording seismograph. Vertical and horizontal graduated boards at midspan will facilitate observations with a transit to measure movement in these two planes. The wind vane and anemometer are mounted on a structural steel platform on the west or ocean side of the bridge at midspan. Both these instruments are electrically connected to motor-driven recording units in the east leg of the south tower. At this point a 24-hour continuous record is maintained from the two wind instruments and the seismograph. With these records it is expected that useful information will be obtained as to the various movements caused under different wind conditions; for example, as in the case of a $72 \mathrm{~m} . \mathrm{p} . \mathrm{h}$. wind such as was recorded during a storm in 1938.

\section{Earthquakes Registered in New Zealand}

DuRING November 1942 ten earthquakes were registered by the seismographs at Auckland, Arapuni, Christchurch, Kaimata, New Plymouth, Tuai and Wellington, according to a seismological report just received (Prov. Bull. No. P-129, November 1942, Dominion Observatory, Wellington W.1, New Zealand). The greatest was on November 10 when the trace amplitude on the $Z$ record was $12 \mathrm{~mm}$. This earthquake began recording with $P$ compression at 11h. 53m. 45s. U.T. from an epicentral distance of $82^{\circ}$ and from an azimuth south-south-west of Christchurch. The shock of November 3 had a focal depth of $350 \mathrm{~km}$., and the next deepest focus occurred on November 7 (180-200 km.). The most intense of the twenty-six earthquakes felt during the month in New Zealand had intensity 5 on the Rossi-Forel scale. This occurred on November 26 at $1 \mathrm{~h}$. $31 \cdot 6 \mathrm{~m}$. U.T. from an epicentre near latitude $41^{\circ} \mathrm{S}$., longitude
$172 \cdot 3^{\circ} \mathrm{E}$. Masterton was most often affected during the month, and Wellington experienced three small shocks on November 3, 7, and 14 .

\section{Activity on Jupiter's South Equatorial Belt}

Mr. B. M. PEEK, director of the Jupiter Section, British Astronomical Association, reports a remarkable outbreak of activity in Jupiter's South Equatorial Belt. This outbreak commenced at some time between February 7 and 11 in System ii longitude $15^{\circ}$ approximately. It is possible that there will be a repetition of the phenomena of 1928-29. The preceding end of the disturbance is advancing rapidly along the north component of the belt in the direction of decreasing System ii longitude : the main features, however, are not rotating so rapidly as System i. In the following portion there are some dark humps on the south component of the belt, the System ii longitude of which is increasing rapidly. Assuming that the rate of drift is maintained, the first of these humps-which is more like a streak than a humpshould reach conjunction with the preceding end of the Red Spot in the first week in April. One important difference between the present outbreak and that of 1928-29 is the appearance of a second centre of disturbance on March 1 about longitude $290^{\circ}$, System ii. Mr. Peek conjectures that the preceding end of the whole disturbed region may soon pass to the north of the Red Spot. If this should occur, it would cause the Red Spot Hollow, which has recently been very faint, to grow darker again.

\section{Variation in $\delta$ Ursæ Majoris}

A BRIEF notice about the variation in the brightness of this star appeared in NATURE of February 6 , p. 165. Additional corroborative evidence is afforded by further observations by Mr. N. F. Knight in North Africa, and Mr. F. M. Holborn at Streatham, London. Mr. Knight's latest observation, made on February 2, gives the magnitude $3 \cdot 5-3 \cdot 6$, and $\mathrm{Mr}$. Holborn had recorded the same magnitude on February 2. Mr. Holborn's most recent observations on February 26 and March 4 show that the star is now practically back to its normal magnitude, $3 \cdot 4$. It may be recalled that $\mathrm{Mr}$. Knight estimated its magnitude as $3 \cdot 8-3 \cdot 9$ on December 10 , and on January 14 and 15 , Mr. Holborn's estimate was $3 \cdot 7$.

\section{Announcements}

Dr. H. Spencer Jones, Astronomer Royal, has been awarded the Gold Medal of the Royal Astronomical Society for his determination of the solar parallax.

Sir BennetT Melvill Jones, professor of aeronautics in the University of Cambridge, has been appointed chairman of the Aeronautical Research Committee in succession to Sir Henry Tizard.

THE University of Sheffield has received a gift of $£ 800$ from an anonymous donor to provide equipment for the Department of Geology after the War.

Mr. A. Wright has resigned from his post of lecturer in mining, on his appointment as senior investigator to the Lancashire and Cheshire Safety in Mines Research Committee.

The Director of the Seismological Institute of the University of Chile reports that a new seismograph consisting of both horizontal and vertical components is being installed at the University in Santiago, Chile. 